International Journal of Engineering \& Technology, 7 (4.20) (2018) 283-286
International Journal of Engineering \& Technology
SPC
Website: www.sciencepubco.com/index.php/IJET
Research paper

\title{
Traffic Characteristics for A Freeway Normal Section at Baghdad City
}

\author{
${ }^{1}$ Jalal, T. S. Al-Obaedi*, ${ }^{2}$ Muhanad Al-temimy, ${ }^{3}$ Amal Ali \\ ${ }^{1}$ University of Al-Qadisiyah, College of Engineering, Roads and Transport Dept., Iraq. \\ ${ }^{2}$ Mustansiriyah University, Faculty of Engineering, Highway and Transportation Dept., Baghdad, Iraq. \\ *Corresponding Author Email: jalal.alobaedi@qu.edu.iq
}

\begin{abstract}
Traffic characteristics at highway sections are usually varying based on many factors including type of highways, geometric design and drivers' behavior at a given area (country). This paper focuses on finding the characteristics for traffic on selected normal freeway section at Baghdad city. Video recordings and speed gun are used to collect data from a basic freeway section within Mohammed Al-Qassim freeway that represents the busiest freeway at the city. The estimated characteristics include the distribution of traffic among the available lanes, desired speed of traffic, lane-changing frequency, and headway distribution. For traffic distribution, it is found that traffic concentrates more in off side lane compared with other lanes for moderate to high flow rates. Regression models have been developed based on the available lane distribution data. The lane found to be increased with the increasing of traffic flow and the desired speeds found to be normally distributed. Examining the headway data shows that the shifted negative exponential distribution can be used to represent the headway distribution for low to intermediate traffic flow only. The findings of this work provides a good database for traffic characteristics for Iraqi highways as little effort has been given in previous research work.
\end{abstract}

Keywords: desired speed, flow distribution, headway distribution, lane changing, traffic characteristics.

\section{Introduction}

Traffic characteristics at highway sections are usually varying based on many factors including type of highways, geometric design and drivers' behavior at a given area.

This work focuses on evaluating of some of freeway's traffic characteristic. The selected parameters include the distribution of traffic among the available lanes, desired speed of traffic, lane-changing frequency, and headway distribution. Such parameters have been selected regarding their importance in traffic flow modelling [1].

Lane utilization or lane distribution refers to the how traffic flow was distributed among the available number of lanes for a directional movement [2]. In the micro-simulation models, the total traffic flow is used as input data and it is divided amongst the lanes by input the traffic flow present either in each lane or by lane distribution equations. Many studies have been evaluated such factor (see [3], for example). However, such factor has little attention based on local traffic studies.

The desired speed represents the higher speed that drivers allowed to use if there is no influence for traffic ahead. This is one of the most input parameters for traffic microsimulation model and therefore the use of actual values will enhance the validity of such models. The desired speeds distribution is regarded as normally distributed based on previous research work but their values are different based on local traffic conditions [1 and 4].

Another important factor in traffic modeling is the headway distribution. The average time headway describes the average arrivals of traffic for a specific location and it is the inverse of flow rate [5].
The description of the headway distribution models was described elsewhere (see [6], for example).

The frequency of lane changing parameter measures the stability of traffic microsimulation models and such parameter were recently used in calibration and validation process of traffic simulation models when the actual and observed lane changing frequencies were compared [1 and 7]. Again, such parameter has limited attention in local traffic studies.

As described above, the above mentioned parameters has little or no attention in local researches. The only closer work is that presented by [ 8 and 9] when they only covered traffic characteristic at flow rate up to $4000 \mathrm{veh} / \mathrm{hr}$ on a section with three lanes. Therefore, this paper focuses on studying the above parameters based on local traffic data, taken from selected freeway site at Baghdad city, and for wide ranges of flow rates.

\section{Methodology}

In order to study the characteristic of traffic at freeway normal section, it is important to select a section located far away from the influence of merging and diverging sections [3 and 10]. This is because the existing of merge/diverge or weaving sections has a great influence on traffic characteristic such as speed and lane utilization [1 and 3]. In addition, the selected section should be far away from the influence of the security checkpoints that are located on some sections of the Iraqi highways for security reasons in the last years. For the purpose of this study, a normal freeway section, that meet the above conditions, located on Mohammed Al-Qassim freeway is selected for data collection process since this freeway represents the busiest freeway at Baghdad city. 
Video recordings technique have been used to collect the data required for estimating lane utilization, lane changing frequency, and headway distribution (see Figure 1 that shows snap shots from the video recordings). For estimating desired speeds, a speed gun "Bushnell Speedster III" has been used as shown in Figure 2. The use of such device in estimating of speeds provides more reliable results than the estimating of speeds from video recordings. The used speed gun device provides speed measurements with an accuracy of $\pm 1 \mathrm{mi} / \mathrm{hr}$ for collecting the desired speed data. The collected data was aggregated for every five minutes' interval so as not to mix flow rates with high fluctuation.

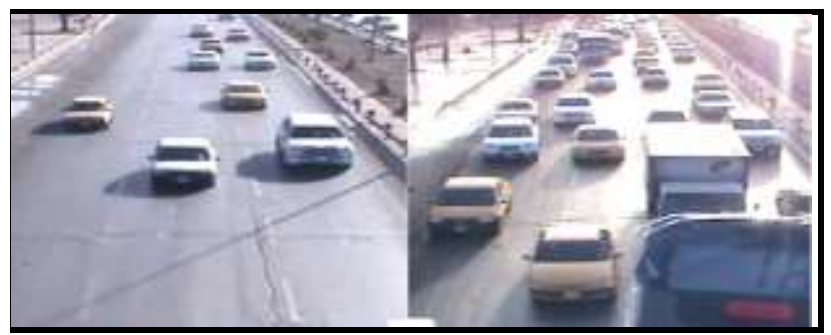

Fig. 1: Normal section in Mohammed Al-Qassim freeway

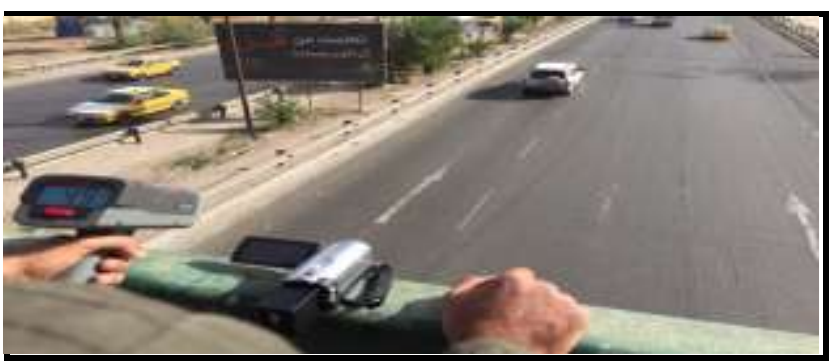

Fig. 2: Speed measured by using Bushnell Speedster III

\section{Results and discussion}

\subsection{Lane distribution behavior}

The distribution of traffic volume among the available three lanes, with respect to the total volume, are shown in Figure 3. The figure shows that at low levels of traffic flow (about $1000 \mathrm{veh} / \mathrm{hr}$ ), the proportion of vehicles occupying all lanes in a similar way. This is because of the freedom of drivers to travel on the inside lane and then leave the outer lane for overtaking. As the total traffic flow increases, the proportion of vehicles using the inside lane (the right lane, lane 1) becomes less than that in the middle lane. In addition, the traffic concentrates more in off side lane (the left lane, lane 3) for moderate to high flow rates (2000 to $5500 \mathrm{veh} / \mathrm{hr}$ ). When flow rates reach capacity (about $6000 \mathrm{veh} / \mathrm{hr}$ ) as shown in the figure 3 , the lane utilization becomes closer at all lanes. This is due to a fact that traffic at capacity usually has same speeds at all lanes and that reduces the need for a lane change.

Regression models have been developed to estimate lane utilization coefficients with the total flow rate as shown in Table 1 . The table presents the proposed models (equations) with their coefficient of determinations $\left(r^{2}\right)$. These equations are suggested to be used as an input for traffic microsimulation models for total flow rates from 500 to $6500 \mathrm{veh} / \mathrm{hr}$. The coefficients are estimated based on Equation 1 [3]

$U_{i}=\frac{\text { Flow rate of lane } i}{\text { Total flow rate }}$

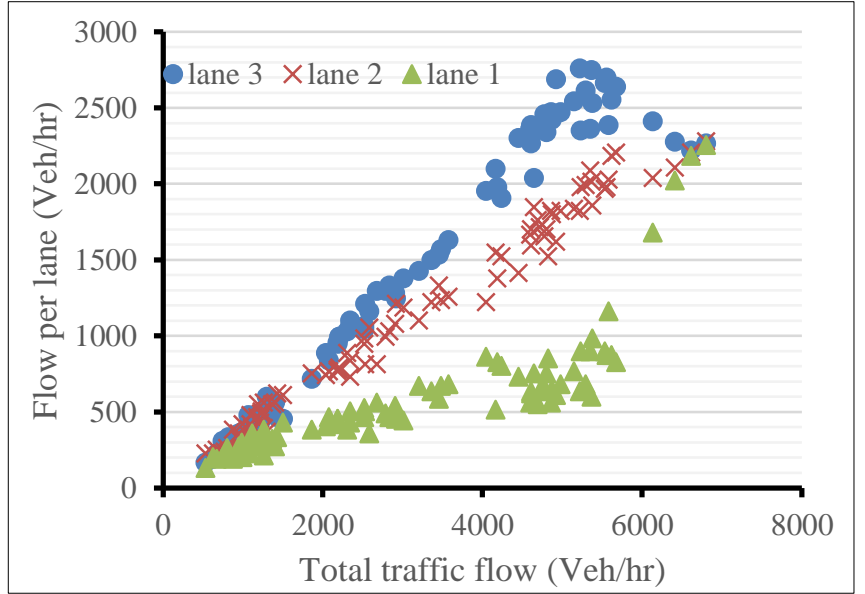

Fig. 3: Traffic flow distribution

Table 1: The proposed models for lane distribution

\begin{tabular}{|c|cc|}
\hline Lane No. & Model & $r^{2}$ \\
\hline 1 & $\mathrm{U} 1=-3 \mathrm{E}-08 \mathrm{x}^{3}+0.0003 \mathrm{x}^{2}-0.1389 \mathrm{x}+271.12$ & 0.774 \\
\hline 2 & $\mathrm{U} 2=-3 \mathrm{E}-09 \mathrm{x}^{3}+3 \mathrm{E}-05 \mathrm{x}^{2}+0.2963 \mathrm{x}+56.306$ & 0.98 \\
\hline 3 & $\mathrm{U} 3=3 \mathrm{E}-08 \mathrm{x}^{3}-0.0003 \mathrm{x}^{2}+0.8427 \mathrm{x}-$ & 0.914 \\
& $327.42768 \mathrm{x}-406.75$ & \\
\hline
\end{tabular}

\subsection{Traffic Composition}

Traffic flow and composition were computed per lane. For the purpose of this study, vehicles were classified for passenger cars (PC), buses and trucks depending on the FHWA vehicle classification. The results of traffic composition are shown in Table 2 which shows that PC represents about $92 \%$ of the total traffic while trucks and buses represents about $8 \%$. It should be noted here that the local agency at Baghdad city prevents trucks from using the city highway before 4 p.m.

Table 2: Traffic composition summary

\begin{tabular}{|c|c|c|c|}
\hline Lane No. & $\%$ of PC & $\%$ of buses & $\%$ of trucks \\
\hline 1 & 89.66 & 0.72 & 9.62 \\
\hline 2 & 89.25 & 0.7 & 10.05 \\
\hline 3 & 96 & 0.56 & 3.4 \\
\hline Total & 92.39 & 0.64 & 6.97 \\
\hline
\end{tabular}

\subsection{Desire Speed}

As defined above, the desired speed of represents the higher speed that a drivers allowed to use if there is no influence for traffic ahead. Duncan [11] reported that from the flow-speed relationship the desired speed could be derived with flow less than $300 \mathrm{veh} / \mathrm{hr}$. The highway capacity manual [2] suggested that according to speedflow relationship, there is approximately constant high speed until flow rate of more than $1200 \mathrm{pc} / \mathrm{hr} / \mathrm{lane}$. In this study and due to the lack of access to a traffic volume of less than $300 \mathrm{veh} / \mathrm{hr}$, the desired speed of vehicles are estimated to be with the range of traffic flow of 600 to $1200 \mathrm{veh} / \mathrm{hr} / \mathrm{lane}$.

The average and standard deviation of desired speeds as well as the sample size used for each lane is presented in Table 3 which shows. As expected, the desired speed for offside lanes are higher than that for the inside lanes which means that the average speed of the first lane (lane1) is less than the average speed of the second lane (lane 2) and the latter is less than the average speed of the third lane (lane 3)

To check whether the sample size is adequate, the selected sample size is compared with the minimum acceptable size according to the procedure described by [12] with an acceptable error of $2 \mathrm{~km} / \mathrm{hr}$. The minimum sample size is estimated from Equation 2 below.

$N=\left(\frac{Z \sigma}{d}\right)^{2}$ 
where

$\mathrm{N}=$ minimum sample size

$\mathrm{Z}=$ number of standard deviations corresponding to the required confidence Level ( $\mathrm{Z}=1.96$ for 95 percent confidence level).

$\sigma=$ standard deviation $(\mathrm{km} / \mathrm{hr})$

$\mathrm{d}=$ limit of acceptable error in the average speed estimate $(\mathrm{km} / \mathrm{hr})$.

Table 4 compares the actual sample size that collected and the minimum required samples to represent the real mean speed, for three lanes. The actual sample size is higher than the minimum for all lanes.

Table 3: Mean speed and stander deviation for each lane

\begin{tabular}{|c|c|c|c|}
\hline Parameter & Lane 3 & Lane 2 & Lane 1 \\
\hline Mean & 99.98 & 79.96 & 57.57 \\
Std. Deviation & 12.94 & 12.89 & 10.82 \\
Sample size & 245 & 235 & 145 \\
\hline
\end{tabular}

Table 4: Comparing minimum and actual sample sizes

\begin{tabular}{|c|c|c|c|c|c|}
\hline $\begin{array}{c}\text { Lane } \\
\text { No. }\end{array}$ & $\begin{array}{c}\text { Actual } \\
\text { sample } \\
\text { size }\end{array}$ & $\begin{array}{c}\sigma \\
(\mathrm{km} / \mathrm{hr})\end{array}$ & $\mathrm{Z}$ & $\begin{array}{c}\mathrm{d} \\
(\mathrm{km} / \mathrm{hr})\end{array}$ & $\begin{array}{c}\text { Mini- } \\
\text { mum } \\
\text { sample } \\
\text { size }\end{array}$ \\
\hline Lane 3 & 245 & 12.94 & 1.96 & 2.0 & 161 \\
Lane 2 & 235 & 12.89 & 1.96 & 2.0 & 160 \\
Lane 1 & 145 & 10.82 & 1.96 & 2.0 & 113 \\
\hline
\end{tabular}

To check the distribution of the desired speeds, SPSS software version 17 is used to examine the normality of speeds distribution. Table 5 shows that speed distributions are normal with to statistical test (Kolmogorov-Smirnov and Shapiro-Wilk) as the significances values are higher than 0.05 . Figures 4,5 , and 6 show the histogram for data distribution for each lane.

Table 5: Summery of SPSS normality test

\begin{tabular}{|c|c|c|c|c|c|c|}
\hline & \multicolumn{2}{|c|}{ Kolmogorov-Smirnova } & \multicolumn{3}{|c|}{ Shapiro-Wilk } \\
\cline { 2 - 7 } & $\begin{array}{c}\text { Statis- } \\
\text { tic }\end{array}$ & df & Sig. & $\begin{array}{c}\text { Statis- } \\
\text { tic }\end{array}$ & df & Sig. \\
\hline Lane 3 & 0.049 & 245 & $0.200^{*}$ & 0.994 & 245 & 0.383 \\
Lane 2 & 0.050 & 235 & $0.200^{*}$ & 0.994 & 235 & 0.547 \\
Lane 1 & 0.057 & 145 & $0.200^{*}$ & 0.991 & 145 & 0.486 \\
\hline
\end{tabular}

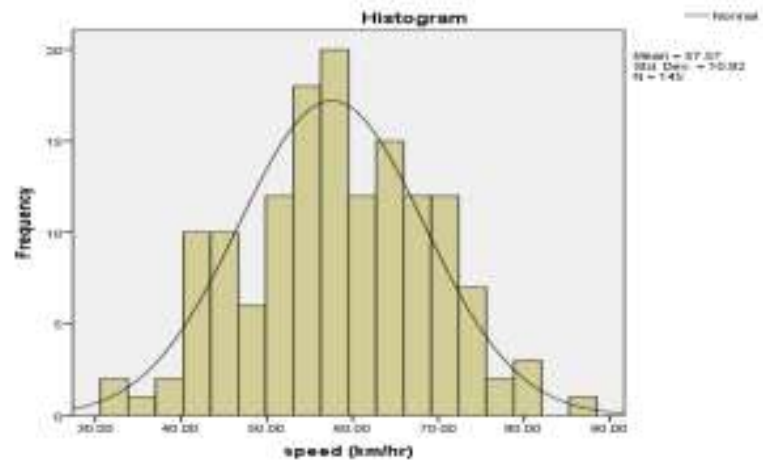

Fig. 4: Speeds histogram for lane 1

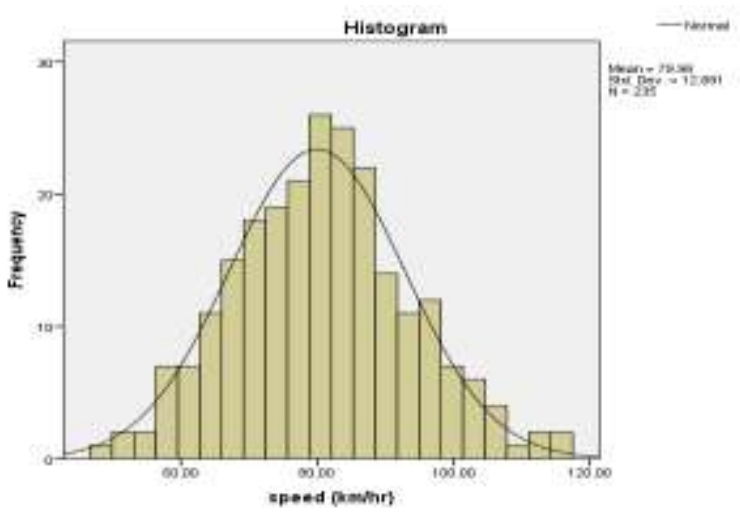

Fig. 5: Speeds histogram for lane 2

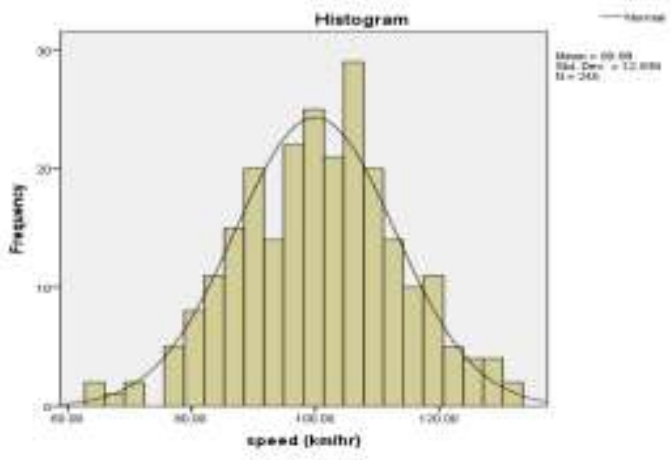

Fig. 6: Speeds histogram for lane 3

\subsection{Headway distribution}

Average time headway represents the average difference in time for successive pairs of vehicles that are arriving a specific section. Several models were proposed to describe vehicle access to a particular section. These models are generally classified into simple models or composite models. The composite model uses two form one for free vehicle and one for restraint vehicle. A simple model using single criteria to describe the arrival vehicle.

Headway data were studied on a per lane basis, and a sample of 30 minutes of the observed headways was chosen during a constant traffic flow based on a study by [13] to eliminate variation and disturbance of the average flow.

Based on literatures (see [1], for example), the shifted negative exponential distribution [6] can be used to describe the headway distribution at low to medium flow rates. This distribution has been used in this study to examine the headway distribution based on local data.

Figures 7, 8 and 9 show the observed and theoretical headways for lanes 1, 2 and 3, respectively. The significance of the differences has been tested using Kolmogorov-Smirnov (K-S) statistical test. The maximum acceptable difference between theoretical and observed headway distribution (Dcr) obtained using Equation (3) and compared with the maximum actual difference (Dmax). The results of the comparison are shown in Table 6 that suggests the validity of the shifted negative exponential distribution for low and medium flow rates similarly to that described in the literature.

$D_{C r}=\frac{1.36}{\sqrt{\text { sample size }}}$

on the above results, the shifted negative exponential distribution can be used to represent the headway distribution for low to intermediate traffic flow, but cannot use for high traffic flow.

Table 6: K-S test result for actual and theoretical headways

\begin{tabular}{|ccccc|}
\hline & Lane 1 & Lane 2 & Lane 3 \\
\hline Flow rate & 582 & 1718 & 2390 \\
$\mathrm{D}_{\max }$ & 0.084 & 0.037 & $0.094^{*}$ \\
$\mathrm{D}_{\text {cr }}$ & 0.094 & 0.057 & 0.028 \\
Shift value & 0.9 & 0.75 & 0.35 \\
Results & Insignificant & Insignificant & significant \\
\hline
\end{tabular}

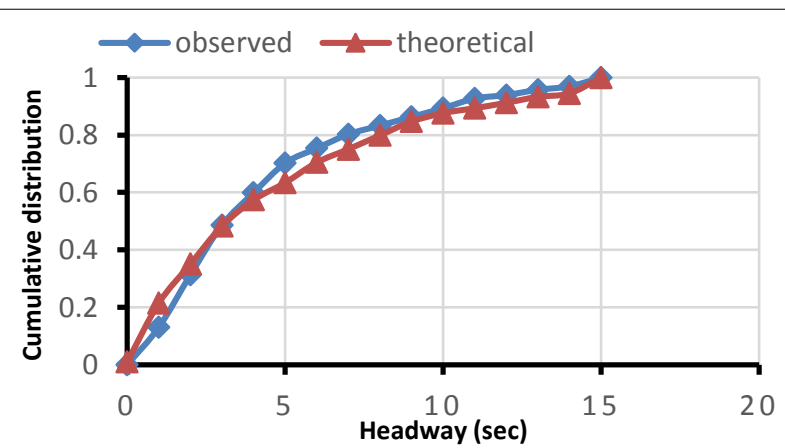

Fig. 7: Theoretical and actual headway for lane 1 


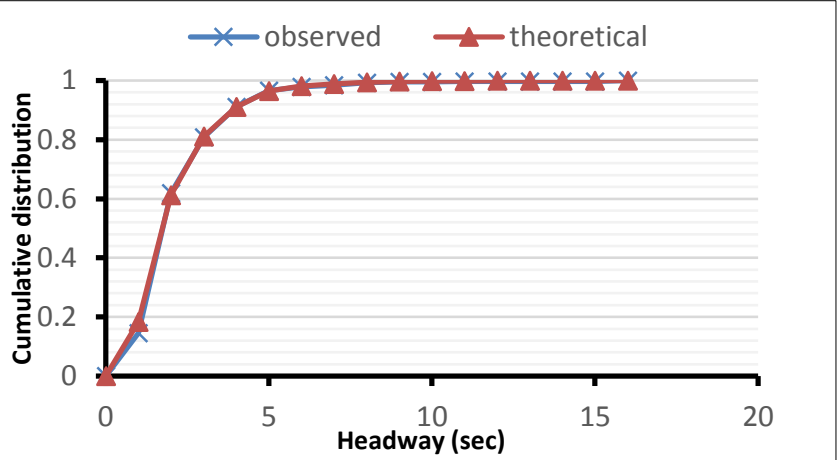

Fig. 8: Theoretical and actual headway for lane 2

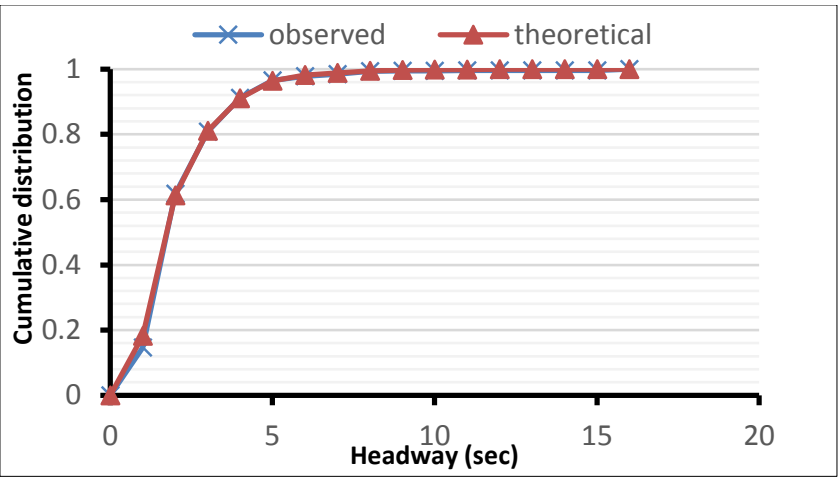

Fig. 9: Theoretical and actual headway for lane 3

\subsection{Lane changing frequency}

Lane changing is one of the factors affecting the quality of the operation traffic. Yousif [14] and Sultan \& McDonald [15] suggested that the frequency of the lane change affected by total traffic flow in the motorway.

In this work, the data are taken from video recording from $\mathrm{Mu}$ hammed Al-Qassim freeway base segment (normal section) with a section length of $200 \mathrm{~m}$ that covered by the camera. This section has no factors that affecting the driver's behavior in lane change process Figure 10 shows that with with taffic flow incresed the fequancy of lane change (FLC) incresed. The results presented in Figure 10 is different than those reported by [14] when he reported that the frequency of lane changes decline at highly flow rates.

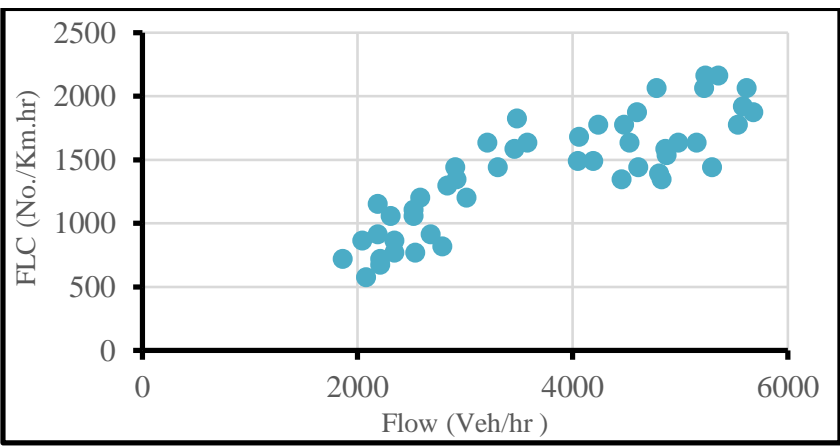

Fig. 10: frequency of lane change for Mohammed Al-Qassim freeway

\section{Conclusions}

This paper focused on some selected traffic characteristics on selected normal freeway section within Mohammed Al-Qassim freeway at Baghdad city. Video recordings and speed gun were used to collect data from the site that represents the busiest freeway at the city. The estimated characteristics include the distribution of traffic among the available lanes, desired speed of traffic, lane-changing frequency, and headway distribution. These parameters have been selected regarding their importance in traffic flow modelling. For traffic distribution, it is found that traffic concentrates more in off side lane (lane 3) compared with other lanes for moderate to high flow rates. Regression models have been developed based on the available lane distribution data. The lane changing frequency has been estimated and found to be increased with the increasing of traffic flow. The distribution of desired speeds found to be normally distributed. Examining the headway data shows that the shifted negative exponential distribution can be used to represent the headway distribution for low to intermediate traffic flow, but cannot use for high traffic flow. The findings of this work provides a good database for traffic charestericts for Iraqi highways as litte effort has been given in previous resaearch work at that field.

\section{References}

[1] Al-Obaedi, J. T. S., (2011) "Development of traffic micorsimulartion model for motorway merges with ramp metering", PhD Thesis, University of Salford, UK.

[2] Transportation Research Board (2010) Highway Capacity Manual (HCM), Washington, D.C.

[3] Yousif, Al-Obaedi and Henson (2013) 'Drivers' lane utilization for UK motorways', Journal of Transportation Engineering, 139(5), pp. $441-447$

[4] Zheng, P. (2003) "A microscopic simulation model of merging operation at motorway onramps", PhD Thesis, University of Southampton, UK.

[5] Zia, F. F. (1992) "Traffic operation at merges on motorways and dual carriageways", PhD Thesis, University of Wales, Cardiff, UK.

[6] Sultan, B. (2000) "The study of motorway operation using a microscopic simulation model", PhD thesis, University of Southampton, UK.

[7] Al-Jameel, H. (2012) "Developing a simulation model to evaluate the capacity of weaving sections", PhD thesis, University of Salford, UK.

[8] Al-Jameel, H. and Kadhim, A. (2018) "Some traffic characteristics of rural roads in Iraq". The 3rd International Conference on Buildings, Construction and Environmental Engineering, Vol. 182.

[9] Al-Jameel, H. (2017) "Lane Changing and Lane Utilization Behavior for three Lane Normal Section in Iraq Traffic Sites". Journal of Babylon, vol.25(1)

[10] Yousif, S., and Hunt, J. (1995) "Modelling lane utilisation on British dual carriageway Roads: Effect on Lane-changing". Traffic Engineering and Control, (36), 580-687.

[11] Duncan N. C. (1976) 'Rural speed-flow relations', Transportation and Road Research Laboratory, LR 705.

[12] Garber, N. J. and Hoel, L. A. (2009) Traffic and Highway Engineering, Fourth edition, Cengage learning.

[13] Hunt, J. G., and Griffiths, J. D. (1980) "Delays at Zebra and Fixed Time Pelican Crossing". Report to Transport and Road Research Laboratory.

[14] Yousif, S. (1993) Effect of Lane Changing on traffic operation for dual carriageway roads with roadworks, PhD Thesis, University of Wales, Cardiff.

[15] McDonald, M., Brackstone, M. and Jeffery, D. (1994) 'Data requirements and sources for the calibration of microscopic motorway simulation models', Proceeding of Vehicle Navigation and Information Systems Conference, pp 233-238.

[16] Federal Highway Administration, available from: http://www.dot.ca.gov/hq/tpp/offices/ogm/trucks/FHWA_VehicleClasses-With-Definitions\%20cs.pdf.

[17] McMahon GT, Gomes HE, Hohne SH, Hu TM, Levine BA \& Conlin PR (2005), Web-based care management in patients with poorly controlled diabetes. Diabetes Care 28, 1624-1629.

[18] Thakurdesai PA, Kole PL \& Pareek RP (2004), Evaluation of the quality and contents of diabetes mellitus patient education on Internet. Patient Education and Counseling 53, 309-313. 